\title{
Preventing catastrophic injury and death in collegiate athletes: interassociation recommendations endorsed by 13 medical and sports medicine organisations
}

\author{
John T Parsons, ${ }^{1}$ Scott A Anderson, ${ }^{2}$ Douglas J Casa, ${ }^{3}$ Brian Hainline (i) ${ }^{1}$
}

\begin{abstract}
- Additional material is published online only. To view please visit the journal online (http://dx.doi.org/10.1136/ bjsports-2019-101090).
\end{abstract}

${ }^{1}$ Sport Science Institute, National Collegiate Athletic Association (NCAA), Indianapolis, Indiana, USA ${ }^{2}$ Athletics, University of Oklahoma, Norman, Oklahoma, USA

${ }^{3}$ Kinesiology, University of Connecticut, Storrs, Connecticut, USA

Correspondence to Dr Brian Hainline, National Collegiate Athletic Association (NCAA), Indianapolis, IN 46206, USA; bhainline@ncaa.org

This article has been copublished in the British Journal of Sports Medicine and Journal of Athletic Training.

Accepted 17 July 2019

Published Online First

19 September 2019

Check for updates

(C) Author(s) (or their employer(s)) 2020. No commercial re-use. See rights and permissions. Published by BMJ.

To cite: Parsons JT,

Anderson SA, Casa DJ,

et al. Br J Sports Med

2020;54:208-215.

The following organisations endorsed this document: American Association of Neurological Surgeons, American Medical Society for Sports Medicine, American Orthopaedic Society for Sports Medicine, American Osteopathic Academy of Sports Medicine, College Athletic Trainers' Society, Collegiate Strength and Conditioning Coaches Association, Congress of Neurological Surgeons, Korey Stringer Institute, National Athletic Trainers' Association, National Strength and Conditioning Association, National Operating Committee for Standards on Athletic Equipment, Sports Neuropsychology Society. The following organisation has affirmed the value of this document: American Academy of Neurology.

\section{ABSTRACT}

The Second Safety in College Football

Summit resulted in interassociation consensus recommendations for three paramount safety issues in collegiate athletics: (1) independent medical care for collegiate athletes; (2) diagnosis and management of sport-related concussion; and (3) year-round football practice contact for collegiate athletes. This document, the fourth arising from the 2016 event, addresses the prevention of catastrophic injury, including traumatic and non-traumatic death, in collegiate athletes. The final recommendations in this document are the result of presentations and discussions on key items that occurred at the summit. After those presentations and discussions, endorsing organisation representatives agreed on 18 foundational statements that became the basis for this consensus paper that has been subsequently reviewed by relevant stakeholders and endorsing organisations. This is the final endorsed document for preventing catastrophic injury and death in collegiate athletes. This document is divided into the following components. (1) Background — this section provides an overview of catastrophic injury and death in collegiate athletes. (2) Interassociation recommendations: preventing catastrophic injury and death in collegiate athletes - this section provides the final recommendations of the medical organisations for preventing catastrophic injuries in collegiate athletes.

(3) Interassociation recommendations: checklist—-this section provides a checklist for each member school. The checklist statements stem from foundational statements voted on by representatives of medical organisations during the summit, and they serve as the primary vehicle for each member school to implement the prevention recommendations. (4) References - this section provides the relevant references for this document. (5) Appendices - this section lists the foundational statements, agenda, summit attendees and medical organisations that endorsed this document.

\section{BACKGROUND}

Data about catastrophic injuries and illnesses in collegiate athletes began with intermittent accounts from print media, and more formally in 1931, through the American Football Coaches Association initiation of the Annual Survey of Football Injury Research. Since 1982, the National Center for Catastrophic Sport Injury Research (NCCSIR) at the University of North Carolina, Chapel Hill, ${ }^{1}$ has been the nation's premier source of catastrophic injury and death related to participation in organised sports at all levels of competition, including college. The NCCSIR monitors, collects and analyses data on catastrophic injuries, illnesses and death and provides publicly available reports about football and other sports. ${ }^{1}$

In order to create enhanced national surveillance abilities for catastrophic injuries, illness and death, the NCCSIR has partnered with the Consortium for Catastrophic Injury Monitoring in Sport. The consortium includes the division on traumatic injury at the Matthew Gfeller SportRelated Traumatic Brain Injury Research Center at the University of North Carolina, Chapel Hill; the division on exertional injury at the Korey Stringer Institute at the University of Connecticut; and the division on cardiac injury in sport at the University of Washington. ${ }^{1}$ Working through the consortium, the NCCSIR has developed new methods of data collection and analysis, including the use of a public-facing online reporting system. ${ }^{2}$

Researchers who study the epidemiology of catastrophic injury and death in sport identify two mechanisms by which these events occur. Traumatic catastrophic injuries, also called direct injuries, are bodily injuries caused directly by participation in a sport activity. ${ }^{1}$ An example of a traumatic catastrophic injury is a spinal cord injury caused by tackling in the sport of football. The three leading causes of death from traumatic injury are traumatic brain injuries, spinal cord injuries and internal organ injuries. ${ }^{1}$ Non-traumatic catastrophic injuries, also known as indirect or exertional injuries, are the 'result of exertion while participating in a sport activity or by a complication that was secondary to a non-fatal injury'. ${ }^{1}$ An example of a non-traumatic catastrophic injury is sudden cardiac arrest in an athlete occurring during a basketball practice. The two leading causes of death from 
non-traumatic injury are sudden cardiac death and exertional injuries. $^{13}$

Enhancing a culture of safety in college sports in general, and college football in particular, is foundational to reducing the occurrence of catastrophic injury and death and the basis for bringing college athletics stakeholders to the first Safety in College Football Summit in 2014, and then reconvening in 2016. The goal of this and any sport safety initiative is protecting the life and the long-term well-being of all athletes.

\section{Catastrophic injury patterns}

Since 1982, the first year for which catastrophic injury/illness data were available across all collegiate sports (ie, National Collegiate Athletic Association (NCAA); National Association of Intercollegiate Athletics; National Junior College Athletic Association), there have been 487 catastrophic injuries or illnesses. Of these, 297 (61\%) were traumatic events and 190 (39\%) were non-traumatic events. ${ }^{1}$ In 2016-2017, the last year for which data across all collegiate sports is available, 19 catastrophic events occurred, five of which were fatal. ${ }^{1}$

Overall, football has the highest number of both traumatic and non-traumatic catastrophic injuries of any collegiate sport. Since 1931, the first year in which football-specific fatality data were collected, there have been 94 traumatic fatalities in college football and 127 non-traumatic fatalities. ${ }^{4}$ More recently, since 1960, there have been 51 traumatic fatalities versus 99 nontraumatic in football. ${ }^{4}$ After adjusting for the total number of participating athletes, football is joined by male gymnastics, female skiing, male ice hockey and female gymnastics for the highest rates of traumatic catastrophic injury. ${ }^{1}$ Traumatic events in football had fallen every decade from 1960 until 1994. That decline is associated with rule modifications based on research, enhanced medical care and education. ${ }^{56}$ Since 1994, the number of traumatic injuries has varied, but at a level generally lower than those of the 1970s and 1980s. ${ }^{1}$

Since 1970 , in both high school and college football, nontraumatic fatalities have outnumbered traumatic fatalities. At both the high school and college level, football has the highest number of non-traumatic catastrophic events. ${ }^{1}$ For example, from 2001 to 2017, the ratio of non-traumatic to traumatic death in collegiate football was $5: 1-35$ non-traumatic deaths compared with seven traumatic fatalities. ${ }^{4}$ Across all levels of football, this ratio is $2: 1 .^{4}$ Non-traumatic deaths in American football have remained relatively steady for more than five decades. Data from $2017^{4}$ reveal the current decade will continue this unfortunate and often preventable trend of non-traumatic death that occurs largely in out-of-season or preseason workouts.

While rule modification has the potential to decrease nontraumatic deaths in certain situations (eg, verification of sickle cell trait decreasing exertional collapse associated with sickle cell trait in Division I football), the policy and procedures to prevent non-traumatic catastrophic death have not kept pace with strength and conditioning sessions and practice sessions that continue to be the setting for record rates of high school and college athlete deaths. For example, of the nine non-traumatic deaths of football players at all levels of the sport in 2017, six occurred during conditioning sessions and one occurred during a strengthening session. ${ }^{1}$ For the $2015-2016$ academic year, six $(15 \%)$ of the 40 non-traumatic catastrophic injuries and illnesses that occurred across all sports and all levels of competition took place during strength and conditioning sessions. ${ }^{1}$ This means that across all sports beside football, non-traumatic injuries are occurring in practice sessions overseen by sport coaches and not during strength and conditioning sessions managed by strength and conditioning professionals.

\section{Policy developments}

Available research provides insight into risk factors for catastrophic injury and has led to policy decisions meant to mitigate those risks. Established research demonstrates that NCAA Division I football athletes with sickle cell trait are at a higher risk of non-traumatic catastrophic events, including death. ${ }^{578}$ In response, the last decade has seen an increase in policy recommendations for the prevention of exertional collapse associated with sickle cell trait (ECAST) in collegiate sport. In 2007, the National Athletic Trainers' Association (NATA) released a consensus statement on sickle cell trait in the athlete. ${ }^{9}$ By 2013 , all three NCAA divisions had adopted legislation requiring confirmation of student-athlete sickle cell trait status before participation. ${ }^{10-12}$ This policy, in tandem with targeted onsite precautions, has resulted in a statistically significant decrease in the number of ECAST deaths in college athletes. ${ }^{13} 14$

Transition periods, defined below, are often associated with poor acclimatisation and fitness levels in athletes returning to activity. ${ }^{1516}$ These concerns have prompted several policy developments. In 2003, the NCAA implemented preseason acclimatisation legislation for football. ${ }^{17} 18$ In the same year, NCAA Division I passed a bylaw ${ }^{19}$ specific to Football Bowl Subdivision and Football Championship Subdivision football that requires any strength and conditioning professional who conducts voluntary off-season weight training or conditioning activities to be certified in first aid and cardiopulmonary resuscitation and to be accompanied by a member of the sports medicine staff who has unchallengeable authority to cancel or modify the workout for health and safety reasons. NCAA Division II passed similar legislation 1 year later. ${ }^{20}$ In Division I, the unchallengeable authority component of this legislation was extended to all sports other than football in situations when a member of the sports medicine staff is present at a workout. In 2012, NATA released interassociation best practices on the prevention of sudden death in collegiate athletes during strength and conditioning drills. ${ }^{15}$ As of 2016, all three NCAA divisions have legislation that requires strength and conditioning professionals to have a certification from either a nationally recognised strength and conditioning certification programme $e^{2122}$ or from an accredited strength and conditioning certification programme. ${ }^{23}$

However, despite these policy developments, catastrophic injuries and fatalities continue to occur. In recent years, most of the fatalities are from non-traumatic causes. These can be mitigated at the member school with appropriate strategies.

\section{Prevention considerations}

Non-traumatic deaths can be mitigated locally through implementation of consensus-based and science-based recommendations. Yet, the number of non-traumatic fatalities are twice those of traumatic fatalities. There have been 99 non-traumatic deaths in collegiate football compared with 51 traumatic deaths since 1960. Just as most of the fatal head injuries and catastrophic cervical spine injuries occurring from 1960 to 1975 can be directly related to the style of play in the sport of football during that time, ${ }^{24-26}$ non-traumatic, exertion-related death is directly related to the conduct and construct of workouts intended to prepare athletes to play sport. ${ }^{5162728}$ Whereas spearing is often the mechanism for traumatic catastrophic injury and death in football, ${ }^{25} 26$ intense, sustained exertion that is not sportspecific and does not include appropriate work-to-rest ratios 
Table 1 Interassociation recommendations: checklist

TRAUMATIC: GENERAL Yes Comments

In all sports, all practices and competitions adhere to existing ethical standards.

In all sports, using playing or protective equipment as a weapon is prohibited during all practices and competitions.

In all practices and competitions, deliberately inflicting injury on another player is prohibited.

All playing and protective equipment, as applicable, meets relevant equipment safety standards and related certification requirements.

There should be a regularly rehearsed emergency action plan consistent with the Concussion Safety Protocol Checklist for all venues at which practices or competitions are conducted.

There is a regularly rehearsed emergency action plan consistent with the Concussion Safety Protocol Checklist for all suspected concussions.

There is a regularly rehearsed emergency action plan consistent with the Concussion Safety Protocol Checklist for all suspected moderate or severe traumatic brain injuries.

There is a regularly rehearsed emergency action plan consistent with the Concussion Safety Protocol Checklist for all suspected cervical spine injuries.

Annual education and prevention strategies about catastrophic injuries are provided to all sports coaches.

Annual education and prevention strategies about catastrophic injuries are provided to all strength and conditioning professionals.

Annual education and prevention strategies about catastrophic injuries are provided to all primary athletics healthcare providers (ie, team physicians and athletic trainers)

Annual education and prevention strategies about catastrophic injuries are provided to all collegiate athletes.

Annual education and prevention strategies about catastrophic injuries are provided to all athletics administrators.

TRAUMATIC: CONTACT/COLLISION HELMETED SPORTS

All contact/collision, helmeted practices and competitions adhere to existing ethical standards.

All contact/collision, helmeted practices and competitions adhere to keeping the head out of blocking and tackling.

All contact/collision, helmeted practices and competitions adhere to prohibiting the use of the helmet as a weapon.

All contact/collision, helmeted practices and competitions adhere to not deliberately inflicting injury on another player.

All contact/collision, helmeted practices and competitions adhere to maintaining and certifying helmets to existing helmet safety standards.

NON-TRAUMATIC:GENERAL

All practices and strength and conditioning sessions adhere to established scientific principles of acclimatisation and conditioning

Conditioning periods are phased in gradually and progressively to encourage proper exercise acclimatisation and to minimise the risk of adverse effects on

health

The first 7 days of any new conditioning cycle are considered a transition periods and a time of physiological vulnerability for athletes.

Transition periods for athletes include but are not limited to returning after an injury or illness.

Transition periods for athletes include, but are not limited to, returning after school break (eg, winter, spring, summer).

Transition periods for athletes include but are not limited to, beginning as a delayed start.

Training and conditioning sessions are appropriately calibrated and include limitations on total volume and intensity of activity, especially during the first

4 days of transition periods.

All workouts have a written plan that is exercise science-based, physiologically sport specific and tailored to the individual.

Workout plans are approved by a credentialed strength and conditioning professional, or the responsible sport coach if a strength and conditioning

professional is not available at the institution.

Components of the workout plan include volume, intensity, mode and duration

Activity location is stated in the workout plan to accommodate venue-specific emergency action planning

Workout plans are reproducible on request and shared with the primary athletics healthcare providers (team physician and athletic trainer) before the session in which they are to be used.

Modification due to hazardous environmental conditions, scheduling considerations, etc, is supported. The amended workout plan maintains the above

principles.

Exercise never is used for punitive purposes.

Educational background, sport experience and credentialing are verified for all strength and conditioning professionals.

All strength and conditioning professionals have a reporting line into the sports medicine or sport performance lines of the institution.

Emergency action plans are developed and rehearsed annually for all venues in which practices or competitions are conducted.

Emergency action plans are developed and rehearsed annually for head and neck injuries.

Emergency action plans are developed and rehearsed annually for cardiac arrest.

Emergency action plans are developed and rehearsed annually for exertional heat illness and heat stroke.

Emergency action plans are developed and rehearsed annually for exertional rhabdomyolysis.

Emergency action plans are developed and rehearsed annually for exertional collapse associated with sickle cell trait.

Emergency action plans are developed and rehearsed annually for any exertional or non-exertional collapse.

Emergency action plans are developed and rehearsed annually for asthma.

Emergency action plans are developed and rehearsed annually for diabetic emergency.

Emergency action plans are developed and rehearsed annually for mental health emergencies.

Strength and conditioning venues have emergency action plans specific to the venue, sport and circumstances.

The institution has adopted requirements for the annual education and training for the prevention of sudden death in sport for strength and conditioning professionals.

The institution has adopted requirements for the annual education and training for the prevention of sudden death in sport for sport coaches

The institution has adopted requirements for the annual education and training for the prevention of sudden death in sport for athletic trainers.

The institution has adopted requirements for the annual education and training for the prevention of sudden death in sport for team physicians.

The institution has adopted requirements for the annual education and training for the prevention of sudden death in sport for collegiate athletes.

The institution has adopted requirements for the annual education and training for the prevention of sudden death in sport for athletics administrators.

Below is a checklist that will help the athletics healthcare administrator to ensure that policies are in place and followed and are consistent with the document, Interassociation recommendations: preventing

catastrophic injury and death in collegiate athletes.

NCAA, National Collegiate Athletic Association. 
coupled with modifications for individual risk and precautions, is too often the mechanism for exertion-related non-traumatic fatality. $591627-29$

In summary, since 1970, traumatic deaths have undergone a steep and steady decline; non-traumatic deaths, however, have remained steady since 1960. The current era, from 2000 to present, is notable for year-round training for football coupled with the highest incidence of non-traumatic sport-related training deaths in football in recorded history. A major goal of this document is to identify a proper combination of strategies to prevent the condition from arising in the first place; ensurance of optimal medical care delivery by key stakeholders onsite; and transparency and accountability in workouts.

\section{INTERASSOCIATION RECOMMENDATIONS \\ Preventing catastrophic injury and death in collegiate athletes}

Best practices for preventing catastrophic injury in collegiate sport are organised into six key areas that are informed by and reflect the 18 consensus foundational statements identified in the online supplementary appendix 1 . These recommendations are summarised and distilled into the checklist found in table 1.

\section{Recommendation 1: sportsmanship}

The principle of sportsmanship is foundational to NCAA athletics competition and creates a moral and ethical framework within which athletics competition occurs. This framework rejects any intentional effort by athletes to use any part of their body, uniform or protective equipment as a weapon to injure another athlete or themselves. ${ }^{30}$ This philosophical commitment is further amplified by express statements about the value of sportsmanship in sport playing rules. ${ }^{31-33}$ The avoidance of on-field or on-court behaviours intended to cause injury to another athlete must become part of the cultural foundation from which all subsequent sport safety initiatives arise.

While acknowledging that football, like other contact/collision sports, is an aggressive, rugged contact sport, the rules of football and of all other sports identify a responsibility shared by all involved to conduct themselves according to a shared ethical code. ${ }^{33}$ This code requires that the head and helmet not be used as a weapon and that unsportsmanlike efforts to deliberately injure an opponent are outside the boundaries of fair and legal play. The act does not need to be purposeful to be considered an infraction.

Given this commitment to sportsmanship, coupled with the considerable safety implications of its violation, the following recommendations regarding deliberate injury to an opponent should be considered in all sports:

1. A player should be ejected immediately from competition (in addition to a particular penalty) for a first infraction.

2. Video replay (when available) after the competition can verify missed calls and could lead to suspension from the next competition. Conferences play a crucial role in this process and should commit themselves to this responsibility.

3. Officials who fail to call such infractions should be educated and/or disciplined appropriately.

4. In helmeted sports, rules should be further developed to prohibit and penalise the initiation of contact with the head/ helmet and should be uniformly enforced.

Recommendation 2: protective equipment

Protective equipment that is used in sport typically must be manufactured and maintained according to performance and safety standards promulgated by standards organisations such as the National Operating Committee on Standards for Athletic Equipment (NOCSAE) ${ }^{34} 35$ and American Society for Testing and Materials International. ${ }^{36}$ Where sport playing rules required equipment to comply with existing standards, the legality of the equipment is dependent on compliance, certification or both with existing standards. For example, current playing rules in the sport of football require that helmets be manufactured and maintained according to standards established by NOCSAE. These standards have been demonstrated to reduce the occurrence of catastrophic brain injury. ${ }^{37}$ In some cases, as with the helmet in the sport of football, equipment must be maintained through a reconditioning process. Where this responsibility exists, member institutions must remain vigilant about ensuring necessary maintenance to ensure the continued safety and legality of protective equipment.

The following should be implemented across all sports:

1. Every member school should establish policy to ensure annual certification, recertification and compliance, as appropriate, with all protective equipment standards.

\section{Recommendation 3: acclimatisation and conditioning}

Many non-traumatic deaths take place during the first week of activity of a transition period in training. ${ }^{15}$ Given this fact, it is imperative to recognise the vulnerability during these periods and to ensure that both proper exercise and heat acclimatisation are implemented.

Transition periods hold particular risk, but absent adherence to established standards, best practices and precautions, collegiate athletes are at risk at all points in the offseason regimen. For example, February and July typically are not transition times, yet from 2000 to 2017, they are the deadliest months of winter and summer training in collegiate football. ${ }^{28}$ Acclimatisation and physiological progression with a basis of exercise science and sport specificity are the cornerstones of safe conditioning and physical activity. It takes approximately 7-10 days for the body to acclimatise to the physiological and environmental stresses placed on it at the start of a conditioning or practice period, especially during periods of warm or hot weather or rapid increase in warm and hot conditions and sudden exposure to altitude. ${ }^{15} 3839$

Acclimatisation, especially heat acclimatisation, can occur only through repeated exposure to a hot environment ${ }^{40}$ while progressively increasing the volume and intensity of physical activity. ${ }^{41}$ Unfortunately, perceived time pressures by coaches coupled with the culture of certain sports that excesses in training make athletes tough, disciplined and accountable contribute to a tendency to overload athletes during transition periods. ${ }^{15} 42$

A minimum expectation is that all strength and conditioning sessions, regardless of when in the year they occur, should be evidence or consensus based; sport-specific; intentionally administered; appropriately monitored, irrespective of the phase of training and not punitive in nature.

For acclimatisation and conditioning, the following direction should be considered for all sports and by any individual responsible for the planning and/or implementation of training and conditioning sessions, whether that be a strength and conditioning professional or a sport coach:

1. Training and conditioning sessions should be introduced intentionally, gradually and progressively to encourage proper exercise acclimatisation and to minimise the risk of adverse effects on health. This is especially important during the first 7 days of any new conditioning cycle, which should be considered a transition period. A lack of progression and sport 
specificity in the volume, intensity, mode and duration of conditioning programmes in transition periods has been noted as a primary factor in non-traumatic fatalities. ${ }^{16}$ Importantly, in this period of year-round sport, new conditioning cycles can occur several times throughout the year and are not limited to the beginning of a competitive season. During transition periods, athletes should be instructed to avoid additional volunteer sessions of physical activity (eg, 7-on-7 drills, pickup games, drill work). Physical activity schedules during transition periods should be well prescribed, accounting for all sources of physical activity in which an athlete engages.

Examples of transition periods for athletes include, but are not limited to:

a. Individual transitions.

1. Athletes new to the programme.

2. Returning after an injury or illness.

3. Any delayed participation relative to the team schedule.

b. Team transitions.

- Resumption of training after an academic break (eg, winter, spring, summer breaks).

2. Training and conditioning sessions should be exercise-science based and physiologically representative of sport and the performance components. Conditioning programmes should begin with work-to-rest ratio intervals appropriate for the goals of the training session and that allow for proper recovery.

3. Collegiate athletes are especially vulnerable to exertional injuries during the first 4 days of transition periods, and the data support that modifications in these periods can greatly decrease risk of catastrophic events. ${ }^{14}$ During this time, training and conditioning sessions should be appropriately calibrated and include limitations on total volume and intensity of activity. This may be accomplished in several ways. For example, holding only one training and conditioning session per day during the transition period may be effective for limiting the volume of physical activity.

a. Properly training during transition periods should also greatly reduce or eliminate rhabdomyolysis, which is largely preventable. Since 2007, 57 NCAA collegiate athletes have been reported as suffering from exertional rhabdomyolysis in nine team outbreaks representing eight different institutions, with 51 of the afflicted collegiate athletes requiring hospitalisation. ${ }^{43}$ Novel overexertion, or exertion caused by new activities or at unaccustomed volume or intensity, is the single most common cause of exertional rhabdomyolysis and is characterised as too much, too soon and too fast in a workout regimen. ${ }^{14}$ Team outbreaks of exertional rhabdomyolysis in NCAA athletes have similarities of irrationally intense workouts designed and conducted by coaches and/or strength and conditioning professionals. ${ }^{43}$

b. When phasing in activity during transition periods, athletics staff members should consider the following:

1. Days/week.

2. Body part.

3. Activity/exercise.

4. Sets/repetitions/distance.

5. Load (per cent of one-repetition maximum, that is, $1 \mathrm{RM})$.

6. Work-rest ratio.

7. Modifications: position; individual; return from injury; environment.

4. All training and conditioning sessions should be documented. In addition, all training and conditioning sessions should: a. Be approved by a credentialed strength and conditioning professional, or by the head sport coach at institutions that do not employ strength and conditioning professionals.

b. Address exercise volume, intensity, mode and duration.

c. Ensure the location of the training and conditioning session is identified in the plan to accommodate venuespecific emergency action planning.

d. Be reproducible on request and be shared with the primary athletics healthcare providers (team physician and athletic trainer) before the session in which they are to be used.

e. Be modified in response to hazardous environmental conditions, scheduling considerations, etc. The amended workout plan should maintain the above principles.

5. A disciplinary system should be developed and applied to strength and conditioning professionals and sport coaches who fail to follow these recommendations. Such penalties could include suspension and/or termination by the member school. Additionally, failure to follow the recommendations could be a reportable offence by member schools to the NCAA.

\section{Recommendation 4: emergency action plan}

There is broad agreement that the most effective way to prevent catastrophic fatalities and manage non-fatal catastrophic events is through a sound and well-rehearsed emergency action plan. $^{13} 15294445$ Venue-specific emergency action plans are a cornerstone of emergency readiness for campus and athletics healthcare providers. ${ }^{38} 46$

Emergency action plans should be readily available to all members of the athletics and emergency medical system community, located both centrally and at each venue at which athletics activities will occur and should be rehearsed with all relevant sports medicine and coaching staff at least once a year. Equipment necessary to execute the emergency action plan should be available to each venue at which athletics activities will occur. Emergency action plan rehearsal also should be incorporated into new employee orientation.

At a minimum, well-rehearsed and venue-specific emergency action plans should be developed for the following catastrophic events:

1. Head and neck injury.

2. Cardiac arrest.

3. Heal illness and heat stroke.

4. Exertional rhabdomyolysis.

5. Exertional collapse associated with sickle cell trait.

6. Any exertional or non-exertional collapse.

7. Asthma.

8. Diabetic emergency.

9. Mental health emergency.

In addition, well-rehearsed and venue-specific emergency action plans should be consistent with the NCAA Concussion Safety Protocol Checklist. ${ }^{47}$ This checklist was created in response to NCAA legislation passed by the Division I conferences with autonomy in January $2015^{47}$ and subsequently by all three divisions. The checklist facilitates the development of a comprehensive and coordinated set of policies to guide institutions in the diagnosis and management of collegiate athlete concussions and in the eventual return to play and return to the classroom by those athletes. Head injury emergency action plans should be created for the following suspected conditions:

1. Concussion. 
2. Moderate or severe traumatic brain injury.

3. Cervical spine injuries.

Special considerations:

1. Cardiac emergencies-research has shown that in sudden cardiac arrest, the probability of survival drops by $7 \%-10 \%$ for every minute of active arrest, whereas the probability of survival is $89 \%$ in properly administered cardiopulmonary resuscitation (CPR) and automated external defibrillators (AED). ${ }^{48}$ The location of AEDs should be documented and should reflect a strategy that ensures their arrival at the scene of a collapse with target goal of collapse-to-shock in less than 3 min. ${ }^{49}$ All AEDs should be checked at least monthly to assure they are fully charged. ${ }^{49}$

2. Exertional heat illness emergencies-exertional heatstroke is a medical emergency that is characterised by extreme hyperthermia $\left(>40.0^{\circ} \mathrm{C} />104^{\circ} \mathrm{F}\right)$ and central nervous system dysfunction such as altered behaviour or decreased consciousness. ${ }^{41}$ To differentiate heatstroke from other acute medical events, primary athletics healthcare providers should be prepared to measure core body temperature using rectal thermometry. Rectal temperature has been demonstrated as the most accurate method for measuring body temperature, whereas other methods such as axillary, tympanic (aural), temporal, oral and skin measurements are not valid or reliable predictors of core temperature. ${ }^{50}$ During warm weather events, but especially preseason practices of fall season sports, resources (eg, equipment and personnel) should be readily available to ensure that full-body ice water immersion can be conducted in a timely manner. Full body immersion in cold water $\left(1.7^{\circ} \mathrm{C}-15.0^{\circ} \mathrm{C} / 35^{\circ}-59^{\circ} \mathrm{F}\right)$ is the most effective immediate treatment of exertional heatstroke, with fatality rates close to zero if the body temperature is brought to less than $40.0^{\circ} \mathrm{C}$ within $30 \mathrm{~min}$ after collapse. ${ }^{41}$ Full-body cold water immersion should be conducted before patient transport and should be continued until the body has cooled to a temperature below $38.9^{\circ} \mathrm{C} / 102^{\circ} \mathrm{F}$. During cold water immersion, body temperature should be continuously monitored with rectal thermometry.

\section{Recommendation 5: responsibilities of athletics personnel}

Physical activity should never be used for punitive purposes. Exercise as punishment invariably abandons sound physiological principles and elevates risk above any reasonable performance reward..$^{15}$ As stated in the 2014-2015 NCAA Sports Medicine Handbook, this principle has been reinforced by the NCAA Committee on Competitive Safeguards and Medical Aspects of Sports. ${ }^{51}$ All athletics personnel, including both sport and strength and conditioning professionals, as well as primary athletics healthcare providers, should intervene when they suspect that physical activity is being used as punishment. Although 'intent' of punishment may be difficult to establish, punishment workouts use unsound physiological principles, as enumerated in this document.

All training and conditioning sessions should be administered by personnel with demonstrated competency in the safe and effective development and implementation of training and conditioning activities, and with the necessary training to respond to emergency situations arising from those activities.

NCAA bylaws in all three divisions require that strength and conditioning professionals have a strength and conditioning certification from either a nationally accredited ${ }^{23}$ or nationally recognised, ${ }^{21} 22$ strength and conditioning certification programme. Additional NCAA bylaws in Division I ${ }^{19} 20$ require that strength and conditioning professionals must be accompanied by members of the sports medicine staff when conducting voluntary, offseason conditioning sessions and that in these situations, the sports medicine staff members have unchallengeable authority to cancel or modify workouts for health and safety reasons.

In Division III, where the presence of full-time strength and conditioning professionals may be rare, and where as a result, sport coaches may provide strength and conditioning services to all collegiate athletes, legislation is more nuanced. Any sport coach can conduct an in-season workout without needing a strength and conditioning certification. Only strength and conditioning professionals with nationally recognised certifications can conduct voluntary workouts in the offseason, and then only during the regular academic year and only if the voluntary workouts are being conducted for all collegiate athletes. ${ }^{21}$ This legislation anticipates a situation where a sport coach is otherwise serving a broader, campus-wide responsibility as strength and conditioning beyond the sport he or she coaches.

The following questions about the strength and conditioning credential should be considered when hiring a strength and conditioning professional:

1. Is the strength and conditioning credential one that reflects attaining of relevant competencies in the delivery of strength and conditioning services to collegiate athletes and team?

2 . Is the credential conferred by a certification programme/process that is nationally accredited?

3. What are the requisite educational standards required for certification eligibility, as well as the continuing education requirements required by the certification programme?

4. Does the certification require CPR and AED certification?

5. Does the certification require a baccalaureate degree or higher, and is it in a degree field with relevance to the provision of strength and conditioning services?

The current state of credentialing across the strength and conditioning profession makes it difficult to ensure that all strength and conditioning professionals have the requisite competency to safely and effectively conduct conditioning sessions. Many organisations currently offer 'strength and conditioning' credentials, though there is significant variability in both the content represented by these credentials and the rigour required to attain them. The complete absence of state regulation further complicates this landscape because there is no clearly established strength and conditioning scope of practice, and therefore, there is no authoritative accounting of the knowledge and skill domains required for the safe and effective practice of a strength and conditioning professional. If carefully considered, the five questions above can assist institutions in identifying strength and conditioning credentials reflecting the attainment of minimal competence in provision of strength and conditioning services. Moreover, the US Registry of Exercise Professionals (see usreps.org/Pages/Default.aspx) contains those strength and conditioning professions with certifications from programmes accredited by the National Commission for Certifying Agencies. NCCA accreditation is considered a marker of quality for certification programmes in the health and/or medical domains.

Although documentation of training and certification are important, an additional problem arises through the increasingly close alignment between sport coaches and strength and conditioning professionals, especially in the sport of football. Strength and conditioning professionals are frequently hired by the head football coach and/or subject to their administrative oversight. This alignment is problematic because it contributes 
to the perception that strength and conditioning professionals are members of the coaching staff rather than independently credentialed strength and conditioning professionals. Such singular alignment and reporting are not consistent with this document. All strength and conditioning professionals should have a reporting line into the sports medicine or sport performance lines of the institution. This includes sport coaches who have responsibility for providing strength and conditioning services across all sport teams.

\section{Recommendation 6: education and training}

Beyond strength and conditioning professionals, each institution should adopt requirements for the education and training of athletics personnel, including as a minimum, but not limited to, strength and conditioning professionals, sport coaches and primary athletics healthcare providers. Education should focus on preventing catastrophic injury and sudden death in sport. Such education and training should occur annually. Regular education not only can serve to improve the recognition and response skills of those who may be involved in a catastrophic event but also can contribute to a heightened state of organisational mindfulness that contributes to an environment of emergency readiness. Education and prevention strategies should be customised for the unique learning needs of relevant stakeholders and their roles in the athletic team.

Such training should include the following:

1. Foundational information regarding emergency action plans.

2. Environmental monitoring (heat/humidity, lightning).

3. Head and neck injuries.

4. Cardiac arrest.

5. Heat illness and heatstroke.

6. Exertional rhabdomyolysis.

7. Exertional collapse associated wiht sickle cell trait.

8. Any exertional or nonexertional collapse.

9. Asthma.

10. Diabetic emergency.

11. Mental health emergency.

12. Proper training principles/principles of periodisation.

Correction notice This article has been corrected since it published Online First. The endorsed society information has been added.

Acknowledgements The authors thank the participants in the 2016 Second Safety in College Football Summit and the organisations who have endorsed and/or given affirmation of value to this document. Finally, the authors are grateful to the NCAA Committee on Competitive Safeguards and Medical Aspects of Sports; Board of Governors; and the membership for their support in guiding this document to become NCAA Association-wide policy.

Contributors All authors substantially contributed to this work. All authors were responsible for the conception and design of the document. JP wrote the first draft of the paper which was then critically revised and approved by all authors. JP and BH are accountable for the work.

Funding The authors have not declared a specific grant for this research from any funding agency in the public, commercial or not-for-profit sectors.

Competing interests None declared.

Patient consent for publication Not required.

Provenance and peer review Not commissioned; externally peer reviewed.

ORCID iD

Brian Hainline http://orcid.org/0000-0002-0233-2434

\section{REFERENCES}

1 Yau R, Kucera KL, Thomas LC, et al. Catastrophic sports injury research: Thirtyfifth annual report fall 1982-Spring 2017. Chapel Hill, NC: National Center for
Catastrophic Sport Injury Research at the University of North Carolina at Chapel Hill, 2018.

2 Kucera KL, Fortington LV, Wolff CS, et al. Estimating the International burden of sportrelated death: a review of data sources. Inj Prev 2019;25:83-9.

3 Van Camp SP, Bloor CM, Mueller FO, et al. Nontraumatic sports death in high school and college athletes. Med Sci Sports Exerc 1995;27:641-7.

4 Kucera KL, Klossner D, Colgate B, et al. Annual survey of football injury research: 1931-2017. Chapel Hill, NC: National Center for Catastrophic Sport Injury Research at the University of North Carolina at Chapel Hill for the American Footbal Coaches Association, National Collegiate Athletic Association, \& National Federal of State High School Associations, 2018

5 Boden BP, Breit I, Beachler JA, et al. Fatalities in high school and College football players. Am J Sports Med 2013;41:1108-16.

6 Cantu RC, Mueller FO. Brain injury-related fatalities in American football, 1945-1999. Neurosurgery 2003;52:846-53.

7 Harmon KG, Drezner JA, Klossner D, et al. Sickle cell trait associated with a $\mathrm{Rr}$ of death of 37 times in national collegiate athletic association football athletes: a database with 2 million athlete-years as the denominator. Br I Sports Med 2012;46:325-30.

8 Harris KM, Haas TS, Eichner ER, et al. Sickle cell trait associated with sudden death in competitive athletes. Am J Cardiol 2012;110:1185-8.

9 National Athletic Trainers' Association. Consensus statement: sickle cell trait and the athlete. Available: https://www.nata.org/sites/default/files/SickleCellTraitAndTh eAthlete.pdf [Accessed 11 Apr 2019].

10 Sickle cell solubility test, division I NCAA Bylaw, §17.1.5.1 2010.

11 Sickle cell solubility test, division II NCAA Bylaw, §17.1.5.1 2012.

12 Confirmation of sickle cell trait status, division III NCAA Bylaw, §17.1.6.4.1 2013.

13 Adams WM, Casa DJ, Drezner JA. Sport safety policy changes: saving lives and protecting athletes. J Ath/ Train 2016;51:358-60.

14 Eichner ER. "A Stitch in Time" and "If 6 was 9": Preventing Exertional Sickling Deaths and Probing Team Rhabdomyolysis Outbreaks. Curr Sports Med Rep 2016:15:122-3.

15 Casa DJ, Anderson SA, Baker L, et al. The inter-association Task force for preventing sudden death in collegiate conditioning sessions: best practices recommendations. $J$ Athl Train 2012:47:477-80.

16 McGrew CA. NCAA football and conditioning drills. Curr Sports Med Rep 2010;9:185-6

17 Five-Day acclimatization period, division I; division II NCAA Bylaw, §17.10.2.4 2003.

18 Five-Day acclimatization period, division III NCAA Bylaw, §17.10.2.2 2004.

19 Strength and conditioning coach first aid / CPR certification and authority of sports medicine staff (FBS / FCS), division I NCAA Bylaw, §13.11.3.7.4 2003.

20 Health and safety oversight, division II NCAA Bylaw, §17.01.2 2004.

21 Strength and conditioning activities as follows, Division III NCAA Bylaw, $\S 17.02 .1 .1 .1$ (j) 2011.

22 Strength and conditioning coach certification, division II NCAA Bylaw, §11.1.7 2016.

23 Strength and conditioning coach certification, division I NCAA Bylaw, §11.1.5 2014.

24 Mueller FO. Catastrophic head injuries in high school and collegiate sports. J Athl Train 2001;36:312-5.

25 Torg JS, Sennett B, Vegso JJ, et al. Axial loading injuries to the middle cervical spine segment. Am J Sports Med 1991;19:6-20

26 Torg JS, Vegso JJ, O'Neill MJ, et al. The epidemiologic, pathologic, biomechanical, and cinematographic analysis of football-induced cervical spine trauma. Am J Sports Med 1990;18:50-7

27 Anderson S. NCAA football off-season training: unanswered Prayers... a Prayer answered. J Athl Train 2017:52:145-8.

28 Anderson SA. The junction boys syndrome. J Strength Cond Res 2012;26:1179-80.

29 DeMartini JK, Casa DJ. Who is responsible for preventable deaths during athletic conditioning sessions? J Strength Cond Res 2011;25.

30 The principle of sportsmanship and ethical conduct, NCAA constitution, §2.4 1996.

31 Andres K. 2018 and 2019 NCAA Men's and Women's Soccer Rules. Indianapolis, IN: National Collegiate Athletic Association, 2018.

32 Hyland A. 2018-19 NCAA Men's Basketball Rules. Indianapolis, IN: National Collegiate Athletic Association, 2018.

33 Redding R. 2017 NCAA football rules and interpretations. Indianapolis, IN: National Collegiate Athletic Association, 2018.

34 National Operating Committee on Standards for Athletic Equipment. Standard performance specification for newly manufactured football helmets. in. Kansas City, KS: NOCSAE, 2015

35 National Operating Committee on Standards for Athletic Equipment. Standard performance specification for recertified football helmets. Kansas City, KS: NOCSAE, 2015.

36 ASTM International. Sports equipment, playing surfaces and facilities; pedestrian/ walkway safety and footwear; amusement rides and devices; snow skiing. Vol 15.07. West Conshohocken, PA: ASTM International, 2016

37 Levy ML, Ozgur BM, Berry C, et al. Analysis and evolution of head injury in football. Neurosurgery 2004;55:649-55.

38 Casa DJ, Guskiewicz KM, Anderson SA, et al. National athletic trainers' association position statement: preventing sudden death in sports. J Ath/ Train 2012;47:96-118. 
39 Garrett AT, Rehrer NJ, Patterson MJ. Induction and decay of short-term heat acclimation in moderately and highly trained athletes. Sports Med 2011:41:757-71

40 Cooper ER, Ferrara MS, Casa DJ, et al. Exertional heat illness in American football players: when is the risk greatest? J Ath/ Train 2016;51:593-600.

41 Casa DJ, DeMartini JK, Bergeron MF, et al. National athletic trainers' association position statement: exertional heat illnesses. J Athl Train 2015;50:986-1000.

42 Eichner ER. Football team rhabdomyolysis: the pain beats the gain and the coach is to blame. Curr Sports Med Rep 2018;17:142-3.

43 Eichner ER. Exertional rhabdomyolysis stays in the news. Curr Sports Med Rep 2016;15:378-9.

44 Drezner JA, Chun JSDY, Harmon KG, et al. Survival trends in the United States following exercise-related sudden cardiac arrest in the youth: 2000-2006. Heart Rhythm 2008;5:794-9.
45 Drezner JA, Courson RW, Roberts WO, et al. Inter-association Task force recommendations on emergency preparedness and management of sudden cardiac arrest in high school and College athletic programs: a consensus statement. J Athl Train 2007:42:143-58.

46 Herring SA, Kibler WB, Putukian M. Sideline preparedness for the team physician: a consensus statement-2012 update. Med Sci Sports Exerc 2012;44:2442-5.

47 Concussion safety protocol management. Available: http://www.ncaa.org/ concussionsafety [Accessed 11 Apr 2019]

48 IOM (Institute of Medicine). Strategies to improve cardiac arrest survival: a time to act. Washington D.C.: Institute of Medicine, 2015.

49 Hainline B, Drezner JA, Baggish A, et al. Interassociation Consensus Statement on Cardiovascular Care of College Student-Athletes. J Am Coll Cardiol 2016;67:2981-95.

50 Casa DJ, Armstrong LE, Kenny GP, et al. Exertional heat stroke: new concepts regarding cause and care. Curr Sports Med Rep 2012;11:115-23.

51 Parsons JT. 2014-2015 NCAA sports medicine Handbook. Indianapolis, IN: National Collegiate Athletic Association, 2014. 